\title{
Análise de Erros e Compreensão de Textos: Comparações entre Diferentes Situações de Leitura ${ }^{1}$
}

\author{
Alina Galvão Spinilloº \\ Luciana Vasconcelos dos Santos Dantas Hodges \\ Universidade Federal de Pernambuco
}

\begin{abstract}
RESUMO - O presente estudo analisou os erros apresentados por crianças com dificuldades de compreensão de textos em duas situações de leitura. As crianças do Grupo 1 realizaram a leitura interrompida de uma história e as do Grupo 2 realizaram a leitura sem interrupção. Após a leitura, as crianças responderam perguntas sobre informações inferenciais. A análise das respostas permitiu identificar quatro tipos de erros referentes à maneira de integrar informações intra e extratextuais. Apesar dos erros serem estáveis em ambas as situações, a leitura interrompida propiciou tentativas de estabelecimento de inferências mais eficientes do que a leitura sem interrupções. Os resultados contribuem para um entendimento psicológico das dificuldades de compreensão textual no que concerne ao estabelecimento de inferências, podendo gerar implicações educacionais.
\end{abstract}

Palavras-chave: dificuldades de compreensão de texto, análise de erros, inferências, crianças.

\section{Error Analysis and Reading Comprehension: Comparisons Between Different Reading Situations}

\begin{abstract}
This study analyzed errors presented by children with difficulties in reading comprehension in two reading conditions. Children in Group 1 were asked to read a story with interruptions, and those in Group 2 had to read the same story without any interruptions whatsoever. After reading, the children answered questions about information of an inferential nature. Analysis of the answers led to the identification of four types of errors, regarding the way intra and extra-textual information is integrated. Although the errors were stable in both situations, the interrupted reading appears to favor attempts to establish inferences. The results contribute to a psychological understanding of the difficulties related to reading comprehension, specifically in the establishment of inferences, with possible educational implications.
\end{abstract}

Keywords: reading comprehension difficulties, error analysis, inferences, children.

A compreensão de textos tem despertado o interesse de pesquisadores e de educadores tanto por sua complexidade como por sua relevância para a aprendizagem de todos os conteúdos escolares desde a educação infantil até os estudos pós-graduados. A literatura na área apresenta modelos de compreensão que descrevem e explicam como este processo ocorre (Glenberg \& Robertson, 1999; Graesser, Singer, \& Trabasso, 1994; Kintsch, 1998) e que fatores o influenciam (Oakhill \& Yuill, 1996; Perfetti, Marron, \& Foltz, 1996; Yuill \& Oakhill, 1991).

Diversos fatores concorrem para a compreensão de textos, sendo todos necessários, porém insuficientes para, de forma isolada, determinar a compreensão. É amplamente reconhecido o papel desempenhado pelos fatores linguísticos, como a capacidade de decodificação, o vocabulário e o conhecimento sintático (Graesser, 2007; Yuill \& Oakhill, 1991); pelos fatores cognitivos, como a memória de trabalho, o monitoramento e a capacidade de estabelecer inferências (Oakhill \& Yuill,

1 Este estudo faz parte da Tese de Doutorado da segunda autora, sob orientação da primeira, na Pós-Graduação em Psicologia Cognitiva da UFPE. Esta pesquisa recebeu apoio do CNPq sob forma de bolsa de estudos conferida à segunda autora.

2 Endereço para correspondência: Universidade Federal de Pernambuco, Pós-Graduação em Psicologia Cognitiva, $\mathrm{CFCH} 8^{\circ}$. andar, Cidade Universitária. Recife, PE. CEP 50670-901. Fone: (81) 2126-8272. E-mail: alinaspinillo@hotmail.com.
1996; Perfetti, Marron \& Foltz, 1996; Yuill \& Oakhill, 1991); e pelos fatores sociais, que envolvem as circunstâncias em que a leitura ocorre (contexto social, objetivos, motivações e expectativas do leitor), os conhecimentos prévios do leitor e sua bagagem sociocultural (Kleiman, 2004; Koch \& Elias, 2007; Solé, 1998).

No que tange aos modelos teóricos que buscam explicar o processo de compreensão textual, o modelo de Construção-Integração (CI) proposto por Kintsch (1998) é o de maior aceitação na área, o qual fornece sustentação teórica ao presente estudo. Nele, a compreensão de textos é concebida como a construção de uma representação mental coerente, elaborada a partir de três instâncias: os elementos textuais, o leitor e a interação entre ambos. O modelo especifica duas fases que ocorrem de forma cíclica durante o processo: a fase de construção, na qual as representações mentais são gradativamente construídas a nível local, a partir dos significados das palavras e das proposições; e a fase de integração, na qual o leitor constrói sentidos ao associar as novas informações às informações antigas já apresentadas no texto e que fazem parte de seus conhecimentos prévios. O modelo considera duas instâncias: o texto-base e o modelo situacional. O texto-base é uma representação fortemente baseada na integração das proposições explicitadas no texto, enquanto o modelo situacional consiste na integração entre o que o texto traz como informação e as elaborações do leitor a partir de seus 
conhecimentos prévios. O modelo situacional seria, então, o espaço em que ocorrem as inferências que possibilitam que o leitor complemente as informações que não estão explicitamente mencionadas no texto. De acordo com este modelo, as inferências participam da integração de informações e a construção de sentidos, sendo a compreensão de textos um processo essencialmente inferencial.

\section{O papel das inferências na compreensão de textos}

A crucialidade das inferências é reconhecida em todos os modelos de compreensão de textos documentados na literatura (Graesser \& Briton, 1996; Graesser, Swamer, Baggett, \& Sell, 1996; Kintsch, 1998) e em pesquisas de diversas afiliações teóricas (Coscarelli, 2003; Marcuschi, 2008; Perfetti, Marron, \& Foltz, 1996; Spinillo, 2008; Vidal-Abarca \& Rico, 2003; Yuill \& Oakhill, 1991). As inferências são estabelecidas a partir da integração de informações intra e extratextuais, ou seja, de conexões entre as passagens do texto entre si, e entre elas e o conhecimento prévio do leitor (conhecimentos linguísticos e de mundo). Muitas das dificuldades de compreensão experimentadas decorrem de problemas no estabelecimento de inferências (Yuill \& Oakhill,1991; Oakhill \& Yuill,1996; Vidal-Abarca \& Rico, 2003; Cain \& Oakhill, 2004; Spinillo, 2008), sendo a capacidade de estabelecer inferências uma das características que mais diferem leitores habilidosos de leitores pouco habilidosos.

As inferências decorrem do fato de que nem tudo está explicitado no texto, tendo o leitor que preencher as lacunas deixadas pelo autor. O texto, portanto, está inacabado e aberto a várias interpretações. No entanto, apesar desta flexibilidade, nem tudo pode ser inferido a partir do texto, havendo inferências desautorizadas, ou seja, erros de compreensão. O presente estudo tem por objetivo analisar a natureza dos erros derivados de dificuldades no estabelecimento de inferências apresentados por crianças que experimentam dificuldades em compreender textos.

\section{Formas de investigar e analisar a compreensão de textos}

Segundo Brandão e Spinillo (1998), entre os diferentes recursos metodológicos adotados na investigação acerca da compreensão de textos, dois tem sido amplamente utilizados: a tarefa de cloze $^{3}$ (Keenan, Potts, Golding, \& Jennings, 1990; Santos, Boruchovitch, \& Oliveira, 2009) e a tarefa de responder perguntas (Keenan, Potts, Golding, \& Jennings, 1990; Yuill \& Oakhill, 1991).

A tarefa de cloze requer o preenchimento de lacunas no texto, com uma palavra adequada em cada lacuna. Segundo Stothard (2004), esta tarefa mostra-se apropriada para avaliar a compreensão relativa ao conhecimento lexical e a relação deste com a habilidade de decodificação;

3 Não existe em português uma tradução para o termo técnico cloze, também referido como técnica ou teste, como pode ser visto nas inúmeras publicações na área que utilizam esta tarefa como um instrumento de diagnóstico e intervenção (ver Santos, Boruchovitch, \& Oliveira, 2009). porém, deixa a desejar quanto à avaliação da compreensão relacionada ao estabelecimento de inferências derivadas da integração de informações intra e extratextuais. Neste caso, responder perguntas sobre o texto parece ser um recurso mais apropriado. As perguntas endereçadas ao leitor para avaliar sua capacidade de compreensão variam quanto ao conteúdo tratado (informação literal ou inferencial) e quanto ao momento em que são apresentadas (antes, durante ou após a leitura do texto). Na presente investigação, o estabelecimento de inferências é examinado a partir de respostas a perguntas inferenciais apresentadas após a leitura de um dado texto.

É comum classificar os leitores em função do desempenho que apresentam em tarefas de compreensão (Nassri, 2002; Yuill \& Oakhill, 1991), diferenciando aqueles com um bom nível de compreensão e aqueles com dificuldades. Entretanto, há classificações alternativas, como é o caso do estudo realizado por Spinillo e Mahon (2007) em que respostas a perguntas inferenciais (de estado, causais e de previsão) foram classificadas em: (i) incoerentes ou improváveis, que estavam em desacordo com o texto; e (ii) coerentes ou prováveis, que eram apropriadas e plausíveis.

Marcuschi (2008) propõe cinco horizontes de compreensão que caracterizam a relação do leitor com o texto: a falta de horizonte consiste em repetições literais do texto; o horizonte mínimo se caracteriza por paráfrases do texto, indicando alguma elaboração sobre ele; o horizonte máximo se caracteriza por uma construção ativa de sentidos, com estabelecimento de inferências apropriadas; o horizonte problemático é aquele em que o leitor insere muitos elementos de conhecimento pessoal, o que favorece uma compreensão inadequada; e o horizonte indevido consiste em uma interpretação errônea, desautorizada pelo texto. Desta forma, os horizontes problemático e indevido expressam dificuldades por parte do leitor.

Também considerando a relação do leitor com o texto, Kopke Filho (2002) menciona três categorias de leitores, de acordo com as bases de sua compreensão: logocêntricos (tomam por base fontes intratextuais), intertextuais (utilizam tanto a informação textual quanto conhecimentos advindos de outras fontes) e egocêntricos (utilizam fontes predominantemente extratextuais).

King (2007) propõe que uma compreensão bem sucedida pode ser literal (rasa) ou inferencial (profunda), e ambas diferem na quantidade e na qualidade das inferências estabelecidas. A compreensão literal toma por base as informações explícitas no texto, de modo que as inferências são derivadas do texto. A compreensão profunda, por sua vez, envolve o estabelecimento de inferências que dependem do conhecimento prévio do leitor. $\mathrm{O}$ conhecimento prévio deriva de informações acumuladas ao longo da história de vida do leitor, variando desde conhecimentos gerais até conhecimentos específicos, adquiridos através de aprendizagens formais ou informais (Coscarelli, 2003; Dell'Isola, 2001).

Apesar de adotarem perspectivas teóricas distintas, as classificações de Marcuschi (2008), Kopke Filho (2002) e King (2007) guardam semelhanças, pois consideram o grau de aproximação ou de afastamento do leitor em relação ao texto e salientam a diferença entre um leitor que se atém ao que está literalmente explicitado no texto 
e aquele que, sem extrapolar indevidamente os limites de significação do texto, é capaz de ir além dele, estabelecendo inferências. Nessas propostas de classificação, a capacidade de estabelecer inferências é colocada como o diferencial entre leitores mais competentes e leitores menos competentes, perspectiva esta também adotada na presente investigação.

É válido ressaltar que tão importante quanto caracterizar o perfil dos leitores é conhecer a natureza das dificuldades que apresentam; isto é, analisar os erros de compreensão que os leitores enfrentam ao procurar estabelecer inferências.

\section{Análise de erros}

Os erros, assim como os acertos, são manifestações de formas de pensar sobre algo. Tal pressuposto remete a um interesse central no campo da psicologia do desenvolvimento cognitivo e da aprendizagem (Castorina, 1988; Inhelder, Sinclair, \& Bovet, 1974; Macedo, 1990; Spinillo, 1995). Apesar de sua relevância, pouco se sabe a respeito dos tipos de erros de compreensão que as crianças apresentam ao tentar estabelecer inferências, visto que há poucos estudos que se voltam para a análise de erros em compreensão de textos. Cain, Oakhill, Barnes e Bryant (2001) analisaram as falhas no estabelecimento de inferências em crianças de 7 e 8 anos, com e sem dificuldades de compreensão de texto. Foram identificadas quatro possibilidades para as causas dos erros: falha em recordar a premissa textual correta; falha em recordar o item relevante da base de conhecimento; falha em integrar ambos; e geração de uma inferência incorreta. Em estudo subsequente, Cain, Oakhill e Elbro (2003) examinaram se crianças seriam capazes de usar contextos narrativos para inferir o significado de novos itens de vocabulário. As crianças liam pequenas histórias que continham palavras inventadas, cujo significado deveria ser inferido a partir do contexto gerado pelo texto. Observou-se que as crianças menos habilidosas apresentaram maior dificuldade do que aquelas com boa habilidade de compreensão. Os autores procederam, então, a uma análise dos erros. As respostas erradas foram classificadas por tipo, de acordo com a adequação ou não ao tema das histórias: palavras com som de rima ou similar; substantivos com sentidos apropriados ao tema; respostas inapropriadas ao tema; e outros tipos de resposta. Os dados mostraram que o padrão de distribuição dos erros não diferia entre os grupos, sugerindo não haver diferenças quanto aos tipos de erros entre crianças com e sem dificuldades de compreensão de texto.

Procurando aprofundar tais discussões, a presente investigação buscou identificar a natureza dos erros que crianças com dificuldades de compreensão apresentam em relação ao estabelecimento de inferências. Procurou-se, ainda, examinar se os erros variariam em função das condições de leitura proporcionadas a essas crianças: uma condição em que o texto era lido de forma contínua; e outra em que o texto era lido de forma interrompida. A ideia era que a leitura interrompida poderia não apenas diminuir o número de erros, como também diminuir a frequência de algum tipo específico de erro.

\section{Método}

\section{Participantes}

Participaram do estudo 40 crianças de ambos os sexos, de baixa renda e com idade média de 9 anos e 5 meses, alunas do $3^{\circ}$ e $4^{\circ}$ anos do ensino fundamental de escolas públicas da cidade do Recife. A escolha de tais participantes decorreu do fato que, conforme depoimento de professores, é comum encontrar-se crianças de escolas públicas que, apesar de alfabetizadas, apresentam dificuldades de compreensão de textos.

\section{Seleção dos participantes}

Trezentas crianças foram examinadas em duas tarefas de sondagem: sondagem da decodificação e sondagem da compreensão. Dessas 300 crianças, 40 participaram do estudo, sendo elas aquelas que (i) não apresentavam problemas de decodificação, obtendo um desempenho acima de 50\% na leitura da história apresentada; e (ii) apresentavam problemas com o estabelecimento de inferências, ou seja, crianças que responderam de forma equivocada a duas das três perguntas inferenciais que lhe foram endereçadas em cada história lida.

\section{Procedimento e Materiais}

Os participantes foram individualmente entrevistados em duas sessões. Na primeira foi inicialmente aplicada a tarefa de sondagem de decodificação e em seguida a tarefa de sondagem da compreensão. A tarefa de sondagem da decodificação (baseada em Leal, 1993) consistia na decodificação em voz alta de um texto pela criança, sendo avaliadas a velocidade de leitura e a decodificação. A tarefa de sondagem da compreensão (baseada em Ferreira e Dias, 2002) consistia na leitura em voz alta de duas histórias pela criança, que era solicitada a responder perguntas sobre informações literais e sobre informações inferenciais.

$\mathrm{Na}$ segunda sessão os participantes foram igualmente divididos em dois grupos, emparelhados quanto à idade, ao sexo e à escolaridade, todos apresentando dificuldade de compreensão de textos no que se refere às inferências, porém sem dificuldades de leitura. Todos foram individualmente solicitados a ler um texto. As crianças do Grupo 1 (G1) faziam uma leitura interrompida de uma história segmentada em sete partes (Apêndice A), usando-se o mesmo texto adotado por Spinillo e Mahon (2007). Ao concluir a leitura de cada parte, a criança era indagada se gostaria de reler a parte em questão antes de prosseguir a leitura. As crianças do Grupo 2 (G2) faziam a leitura da mesma história; mas sem interrupções, podendo ler toda a história novamente, caso desejassem. Concluída a leitura do texto, eram oralmente apresentadas aos participantes de ambos os grupos, uma a uma e em ordem fixa, as seguintes perguntas: Do que fala esta história? Qual foi o fato mais importante da história? O que os meninos mais queriam? Qual era o problema que os meninos tinham? Por que eles tinham esse problema? Como o problema foi resolvido? Quem resolveu o problema? As respostas foram gravadas em áudio com gravador digital e transcritas para análise. 
Tabela 1. Categorias de Respostas e seus Exemplos.

\begin{tabular}{|c|c|}
\hline Categorias & Exemplos* \\
\hline I - Não responde & "Não sei”. "Me esqueci”. "Não lembro". \\
\hline $\begin{array}{l}\text { II - Respostas problemáticas ou indevidas, que se } \\
\text { caracterizam como erros de compreensão }\end{array}$ & Exemplos dessas respostas são fornecidos e discutidos adiante. \\
\hline $\begin{array}{l}\text { III - Respostas vagas ou imprecisas que, embora corretas, } \\
\text { trazem poucas informações ou detalhes precisos }\end{array}$ & $\begin{array}{l}\text { E: O que os meninos mais queriam? } \\
\text { C: Brincar. }\end{array}$ \\
\hline $\begin{array}{l}\text { IV - Respostas precisas, que, além de corretas, se } \\
\text { caracterizam por fornecerem informações específicas e } \\
\text { com alto grau de explicitação }\end{array}$ & $\begin{array}{l}\text { E: Como o problema foi resolvido? } \\
\text { C: Pela turma de Pedrinho e seus amigos. Porque limparam a... } \\
\text { Como é o nome? Limparam o... Como é o nome? O campinho. } \\
\text { E Seu Nicolau esteve maior felicidade; aí arrancou a placa. E } \\
\text { assim, eles voltaram jogar lá. }\end{array}$ \\
\hline
\end{tabular}

* Nestes e em outros exemplos, convencionou-se E para a fala da examinadora e C para a fala da criança.

\section{Análise dos dados}

As respostas dos participantes foram inicialmente classificadas em quatro categorias elaboradas em função dos dados obtidos nesse estudo. Na Tabela 1 constam exemplos e uma breve descrição dessas categorias.

As respostas foram analisadas por dois juízes independentes, obtendo-se um percentual de concordância de $75 \%$ entre eles. As discordâncias foram analisadas por um terceiro juiz também independente, cujo julgamento foi considerado final.

Considerando os objetivos deste estudo, as respostas incorretas foram, através de discussão entre os juízes, analisadas, identificando-se quatro tipos de erros:

Tipo 1 (opinião): a criança fornece uma opinião que expressa preferência ou avaliação de natureza moral sobre os personagens, os eventos, ou sobre a conclusão da história.

Exemplo 1:

E: Do que fala esta história?

C: De Pedrinho. Pedrinho é uma pessoa boa.

Exemplo 2:

E: Qual foi o fato mais importante da história?

C: Mais importante porque eles tão limpando aquela cidade, que eles tão fazendo a coisa certa ali pra aquela cidade, pra aquela casa.

No Exemplo 1, a resposta expressa um julgamento acerca da índole do personagem principal; enquanto no Exemplo 2 a resposta expressa uma avaliação de natureza moral. Nos dois casos a resposta versa sobre uma avaliação acerca do texto como um todo ou sobre algo em particular, porém sem ater-se a informações cruciais que são o cerne da história.

Tipo 2 (repetição de informação intratextual): a criança menciona uma passagem do texto, de forma literal ou parafraseada; mas que não responde a pergunta.

Exemplo 3:

E: Qual foi o fato mais importante da história?

$C$ : A mãe sentiu um aperto no coração.
Exemplo 4:

E: Qual o assunto dessa história?

C: Pedrinho piscou pros amigos e disse 'Pedrinho'.

Seja através de uma menção literal (Exemplo 3) ou de uma paráfrase (Exemplo 4), os fatos tratados são de pouca importância para a trama, sugerindo que a criança não foi capaz de discriminar as informações relevantes das irrelevantes.

Tipo 3 (integração de informações intratextuais): a criança integra informações intratextuais que estão literalmente expressas no texto, derivando uma informação desautorizada.

Exemplo 5:

E: O que os meninos mais queriam? (P3)

C: Que ele não... não vendesse a casa, e que os menino ficasse morando lá.

Neste exemplo, duas informações intratextuais são integradas: o fato de Seu Nicolau querer vender algo e o fato de que ele era dono de muitas casas na rua, incluindo a de Pedrinho. Porém, ao integrar estas informações, a criança gerou uma informação desautorizada (vender a casa de Pedrinho) que não corresponde ao que foi veiculado pelo texto (vender o campinho).

Tipo 4 (integração de informação intratextual e extratextual): a criança integra informação intratextual e extratextual; porém esta integração gera uma extrapolação e distorção que resultam em uma compreensão não autorizada pelo texto.

Exemplo 6:

E: Qual era o problema que os meninos tinham?

C: Porque as mães não deixavam eles brincar na rua.

E: Por que eles tinham esse problema?

C: Porque, por causa dos carros, dessas coisas que podem atropelar e matar.

No exemplo 6, o leitor inferiu as causas para a proibição da mãe com base em seu conhecimento de mundo (informação extratextual) de que carros atropelam e podem matar. No entanto, este conhecimento de mundo que foi acionado pelo texto não é uma informação apropriada para justificar a exis- 
tência do problema que os personagens da história tinham. A criança, de forma equivocada, considerou o fato da mãe não permitir a brincadeira na rua, e não a possível venda do terreno, como o problema central que norteia a trama.

\section{Resultados}

O teste U de Mann-Whitney não detectou diferenças significativas entre os grupos quando comparados entre si. Porém, o teste de Friedman mostrou haver diferenças dentro de cada grupo entre as categorias tanto no $\mathrm{G} 1\left(\chi^{2}=28,48 ; \mathrm{gl}=3\right.$; $\mathrm{p}<0,001)$ como no $\mathrm{G} 2\left(\chi^{2}=31,55 ; \mathrm{gl}=3 ; \mathrm{p}<0,001\right)$. Em ambos os grupos houve uma concentração de respostas da Categoria III ( $\mathrm{G} 1=52,8 \%$; G2 $=54,3 \%$ ), sendo raras as respostas da Categoria I ( $\mathrm{G} 1=9,3 \% ; \mathrm{G} 2=10,7 \%)$. Esses dados indicam que a situação de leitura não influenciou a distribuição das respostas nas categorias, e que os dois grupos tiveram um percentual de erros bastante semelhante (Tabela 2).

Tabela 2. Número (e Porcentagem) de Categorias de Respostas em cada Grupo.

\begin{tabular}{ccc}
\hline Categorias & $\begin{array}{c}\text { Grupo 1 } \\
\text { (com interrupções) } \\
(\mathbf{n = 1 4 0 )}\end{array}$ & $\begin{array}{c}\text { Grupo 2 } \\
\text { (sem interrupções) } \\
\text { (n=140) }\end{array}$ \\
\hline I & $13(9,3)$ & $15(10,7)$ \\
II & $26(18,6)$ & $30(21,4)$ \\
III & $74(52,8)$ & $76(54,3)$ \\
IV & $27(19,3)$ & $19(13,6)$ \\
\hline
\end{tabular}

Nota. Categoria I - Não Responde; Categoria II - Resposta Problemática ou Indevida; Categoria III - Resposta Imprecisa; Categoria IV - Resposta Precisa.

Considerando o objetivo da presente investigação, conduziu-se uma análise dos tipos de erros. Para isso, apenas as respostas da Categoria II foram objeto de discussão, como apresentado na Tabela 3. Devido aos baixos valores das células, não foi possível aplicar um tratamento estatístico adequado, sendo os resultados discutidos em termos de tendências.

Duas principais diferenças entre grupos foram observadas: erros Tipo 4 (integração de informação intratextual e extratextual ) são mais frequentes no G1 $(34,4 \%)$ do que no G2 (9,4\%); enquanto erros Tipo 2 são mais observados entre as crianças do G2 $(43,7 \%)$ do que nas do G1 $(31,1 \%)$. Ao que parece, os erros das crianças que faziam a leitura com interrupção $(\mathrm{G} 1)$ envolviam a integração de informações de diferentes fontes (intra e extratextuais). Por sua vez, os erros das crianças que faziam a leitura sem interrupção (G2) se limitavam a repetições de informações literais que eram tratadas de forma isolada. Desta forma, parece que a leitura interrompida propiciou a tentativa de integração de informações.

Considerando que os erros do Tipo 4 refletem a tentativa do leitor em integrar informações de diferentes fontes (intra e extratextual), pode-se dizer que a situação de leitura
Tabela 3. Número (e Porcentagem) de Tipos de Erro em cada Grupo.

\begin{tabular}{ccc}
\hline $\begin{array}{c}\text { Tipos de } \\
\text { Erro }\end{array}$ & $\begin{array}{c}\text { Grupo 1 } \\
\text { (com interrupções) } \\
(\mathbf{n = 2 9})^{\mathrm{a}}\end{array}$ & $\begin{array}{c}\text { Grupo 2 } \\
\text { (sem interrupções) } \\
(\mathbf{n}=\mathbf{3 2})^{\mathrm{a}}\end{array}$ \\
\hline 1 & $3(10,3)$ & $5(15,6)$ \\
2 & $9(31,1)$ & $14(43,7)$ \\
3 & $7(24,2)$ & $10(31,3)$ \\
4 & $10(34,4)$ & $3(9,4)$ \\
\hline
\end{tabular}

Nota. Tipo 1 - Opinião; Tipo 2 - Repetição de informação intratextual; Tipo 3 - Integração de informações intratextuais; Tipo 4 - Integração de informação intratextual e extratextual.

${ }^{a}$ Como havia respostas mistas que envolviam mais de um tipo de erro, o valor de $\mathrm{n}$ em cada grupo foi maior do que o número de respostas classificadas na Categoria II (Grupo 1 = 13; Grupo $2=15$ ).

interrompida parece propiciar tentativas de estabelecimento de inferências. Segundo a perspectiva teórica adotada, a integração de informações é essencial no processo de compreensão, visto que ela permite o estabelecimento de inferências. Em sendo assim, torna-se relevante examinar se o erro apresentado expressa uma tentativa do leitor em integrar informações. Analisando os erros por este prisma, é possível agrupá-los em erros em que não se evidencia a tentativa de integrar informações (Tipo 1 + Tipo 2) e erros em que se evidencia a tentativa de integrar informações (Tipo 3 + Tipo 4). A Tabela 4 ilustra esta análise.

Tabela 4. Número (e Porcentagem) de Erros Com ou Sem Integração em cada Grupo.

\begin{tabular}{ccc}
\hline Erros & $\begin{array}{c}\text { Grupo 1 } \\
\text { (com interrupções) } \\
(\mathbf{n = 2 9 )}\end{array}$ & $\begin{array}{c}\text { Grupo 2 } \\
\text { (sem interrupções) } \\
(\mathbf{n}=\mathbf{3 2})\end{array}$ \\
\hline $\begin{array}{c}\text { Sem Integração } \\
\text { Explícita }\end{array}$ & $12(41,4)$ & $19(59,3)$ \\
$\begin{array}{c}\text { Com Integração } \\
\text { Explícita }\end{array}$ & $17(58,6)$ & $13(40,7)$ \\
\hline
\end{tabular}

O teste Wilcoxon e o teste U de Mann- Whitney não revelaram diferenças significativas, indicando que a situação de leitura não influenciou a capacidade da criança em integrar informações intra e extratextuais.

\section{Discussão}

Tanto os modelos de compreensão de textos como as pesquisas empíricas na área fornecem um quadro expressivo de informações acerca da compreensão de textos. Contudo, pouco se sabe a respeito dos erros que as crianças com dificuldades de compreensão apresentam. Inserida em uma perspectiva de desenvolvimento em que os erros (assim como os acertos) são considerados indicadores que permitem estabelecer inferências sobre formas de pensar, a presente 
investigação contribuiu para o entendimento da natureza das dificuldades específicas que as crianças apresentam ao estabelecer inferências.

Uma primeira conclusão derivada dos dados neste estudo foi que os erros de compreensão não podem ser considerados em bloco, uma vez que são de natureza distinta. A análise realizada permitiu identificar diferentes tipos de erros especificamente relacionados ao estabelecimento de inferências, sendo três deles particularmente interessantes: (i) erros em que o texto é fortemente considerado, sem haver uma tentativa de integração de informações intratextuais (Tipo 2); (ii) erros em que o texto é fortemente considerado, mas se observa uma tentativa de integração de informações intratextuais; porém de forma desautorizada pelo texto (Tipo 3); e (iii) erros em que tanto o texto como os conhecimentos prévios do leitor são considerados, observando-se uma tentativa de integração de informações intratextuais e extratextuais; porém de forma desautorizada pelo texto (Tipo 4).

Uma segunda conclusão é que os tipos de erros expressam diferentes níveis de dificuldade, havendo erros mais elementares e erros mais elaborados. Os erros mais elementares seriam aqueles em que o leitor trata as informações de forma isolada (ou não verbaliza as possíveis relações entre as informações). Os erros mais elaborados, por sua vez, seriam aqueles em que tais relações são expressas nas respostas dadas, indicando o estabelecimento de inferências. Essas inferências, entretanto, não são autorizadas pelo texto, expressando equívocos, distorções ou extrapolações indevidas.

Outras conclusões podem ser derivadas a partir da comparação das duas situações de leitura. Uma é que o fato da leitura ser ou não interrompida não afeta o percentual de acertos e erros encontrados. Isso sugere que as dificuldades experimentadas são estáveis, permanecendo mesmo quando o leitor entra em contato com o texto parte por parte, como ocorre na leitura com interrupções. Entretanto, quando se analisa os tipos de erros, diferenças entre as duas situações de leitura são observadas: a leitura interrompida parece propiciar a integração de informações intratextuais e extratextuais, visto que erros Tipo 4 eram mais frequentes nesta situação de leitura. Esta foi a única diferença entre as duas situações. Ao que parece, a leitura interrompida pode proporcionar ao leitor a oportunidade de tentar associar seus conhecimentos prévios ao que lê no texto. Porém, essa integração não é suficiente para gerar uma inferência apropriada, e a dificuldade de compreensão persiste. Assim, a situação de leitura interrompida parece favorecer um nível de processamento mais profundo (ver King, 2007), no qual o leitor traz seus conhecimentos prévios e os integra às informações textuais. No entanto, é relevante enfatizar que os erros que envolvem a integração de informações podem ser considerados erros mais elaborados que os demais, pois o leitor considera informações intratextuais e extratextuais, num processo de construção de sentidos que envolve o estabelecimento de inferências, e assim se aproxima da compreensão textual eficiente.

Para finalizar, a análise de erros permite esclarecer a natureza das dificuldades experimentadas por leitores com problemas de compreensão textual. Partindo do pressuposto de que a compreensão de texto deve ser considerada um ob- jeto de ensino que precisa ser tratado didaticamente, como afirmado por Spinillo (2008), a análise de erros pode auxiliar o professor a identificar a natureza das dificuldades dos alunos e, assim, promover situações de ensino especificamente direcionadas para essas dificuldades, buscando promover níveis mais sofisticados de compreensão.

\section{Referências}

Brandão, A. C. P., \& Spinillo, A. G. (1998). Aspectos gerais e específicos na compreensão de textos. Psicologia: Reflexão e Crítica, 11 (2), 235-272.

Brandão, A. C. P., \& Spinillo, A. G. (2001). Produção e compreensão de textos em uma perspectiva de desenvolvimento. Estudos de Psicologia, 6 (1), 55-66.

Cain, K., \& Oakhill, J. (2004). Reading comprehension difficulties. In T. Nunes \& P. Bryant (Eds.), Handbook of children's literacy (pp. 313-338). London: Kluwer Academic Press.

Cain, K., Oakhill, J., Barnes, M., \& Bryant, P. (2001). Comprehension skill, inference-making ability, and their relation to knowledge. Memory \& Cognition, 29 (6), 850-859.

Cain, K., Oakhill, J. V., \& Elbro, C. (2003). The ability to learn new word meanings from context by school-age children with and without language comprehension difficulties. Journal of Child Language, 30, 681-694.

Castorina, J. A. (1988). Psicologia genética: aspectos metodológicos e implicações pedagógicas. Porto Alegre: Artes Médicas.

Coscarelli, C. V. (2003). Inferência: afinal o que é isso? Belo Horizonte: FALE/UFMG. Retrieved from http://bbs.metalink. com.br/ 1 coscarelli/ publica. htm

Dell'Isola, R. L. P. (2001). Leitura: inferências e contexto sociocultural. Belo Horizonte: Formato Editorial.

Ferreira, S., \& Dias, M. (2002). Compreensão de leitura: Estratégias de tomar notas e da imagem mental. Psicologia: Teoria e Pesquisa, 18, 51-62.

Glenberg, A. M., \& Robertson, D. A. (1999). Indexical understanding of instructions. Discourse Processes, 28, 1-26.

Graesser, A. C. (2007). An introduction to strategic reading comprehension. In D. S. McNamara (Ed.), Reading comprehension strategies: theories, interventions, and technologies (pp. 3-26). New York, NY: Lawrence Erlbaum.

Graesser, A. C., \& Britton, B. K. (1996). Five metaphors for text understanding. In B. K. Britton \& A. C. Graesser (Eds.), Models of understanding text (pp. 341-351). Mahwah, NJ: Lawrence Erlbaum.

Graesser, A. C., Singer, M., \& Trabasso, T. (1994). Constructing inferences during narrative text comprehension. Psychological Review, 101 (3), 371-395.

Graesser, A. C., Swamer, S., Baggett, W. B., \& Sell, M. A. (1996). New models of deep comprehension. In B. K Britton \& A. C. Graesser (Eds.), Models of understanding text (pp. 1-32). Mahwah, NJ: Lawrence Erlbaum.

Inhelder, B., Sinclair, H., \& Bovet, M. (1974). Aprentissage et structures de la connaissance. Paris: PUF.

Keenan, J. M., Potts, G. R., Golding, J. M., \& Jennings, T. M. (1990). Which elaborative inferences are drawn during reading? A question of methodologies. In D. A. Balota, G. B. Flores d'Arcais \& K. Rayner (Eds.), Comprehension processes in reading (pp. 377-402). New Jersey: Lawrence Erlbaum. 
King, A. (2007). Beyond literal comprehension: a strategy to promote deep understanding of text. In D. S. McNamara (Ed.), Reading comprehension strategies: theories, interventions, and technologies (pp. 267-290). New York, N. Y.: Lawrence Erlbaum.

Kintsch, W. (1998). Comprehension: a paradigm for cognition. Cambridge: Cambridge University Press.

Kleiman, A. (2004). Texto e leitor: aspectos cognitivos da leitura. Campinas, SP: Pontes.

Koch, I. V., \& Elias, V. M. (2007). Ler e compreender: os sentidos do texto. São Paulo: Contexto.

Kopke Filho, H. (2002). Aspectos interdisciplinares nos processos da leitura e da compreensão de textos. In G. P. Witter (Ed.), Psicologia: tópicos gerais (pp. 73-84). Campinas, SP: Editora Alínea.

Leal, T. F. (1993). Uso do contexto na aquisição da leitura. Dissertação de Mestrado, Universidade Federal de Pernambuco, Recife, PE.

Macedo, L. de (1990). Para uma visão construtivista do erro no contexto escolar. In C. de T. Aguiar (Ed.), Coletânea de textos de psicologia (pp. 75-84). Secretaria da Educação/ Coordenadoria de Estudos e Normas Pedagógicas: São Paulo.

Marcuschi, L. A. (2008). Produção textual, análise de gêneros e compreensão. São Paulo: Parábola Editorial.

Nassri, R. C. B. M. (2002). Compreensão de leitura em universitários de direito e medicina. In G. P. Witter (Ed.), Psicologia: tópicos gerais (pp. 179-192). Campinas, SP: Editora Alínea.

Oakhill, J., \& Yuill, N. (1996). Higher order factors in comprehension disability: Processes and remediation. In C. Cornoldi \& J. Oakhill (Eds.), Reading comprehension difficulties: processes and intervention (pp. 69-92). Mahwah, NJ: Lawrence Erlbaum.

Perfetti, C. A., Marron, M. A., \& Foltz, P. W. (1996). Sources of comprehension failure: theoretical perspective and case studies. In C. Cornoldi \& J. Oakhill (Eds.), Reading comprehension difficulties: processes and intervention (pp. 137-165). Mahwah, NJ: Lawrence Erlbaum.
Santos, A. A. A., Boruchovitch, E., \& Oliveira, K. L. (2009). Cloze: um instrumento de diagnóstico e intervenção. São Paulo, SP: Casa do Psicólogo.

Solé, I. (1998). Estratégias de leitura. Porto Alegre, RS: Artmed. Spinillo, A. G. (1995). Avaliação da aprendizagem numa perspectiva cognitiva. Psychologica, 14, 83-99.

Spinillo, A. G. (2008). O leitor e o texto: desenvolvendo a compreensão de textos na sala de aula. Revista Interamericana de Psicología/Interamerican Journal of Psychology, 42 (1), 29-40.

Spinillo, A. G., \& Mahon, E. R. (2007). Compreensão de texto em crianças: comparações entre diferentes classes de inferência a partir de uma metodologia on-line. Psicologia: Reflexão e Crítica, 20 (3), 463-471.

Stothard, S. E. (2004). Avaliação da compreensão de leitura. In M. Snowling \& J. Stackhouse (Eds.), Dislexia, fala e linguagem. Um manual do profissional (pp. 121-141). Porto Alegre: Artmed.

Vidal-Abarca, E., \& Rico, G. M. (2003). Por que os textos são tão difíceis de compreender? As inferências são a resposta. In A. Teberosky \& C. Oller (Eds.), Compreensão de leitura: a língua como procedimento (pp. 139-154). Porto Alegre: Artmed.

Yuill, N., \& Oakhill, J. (1991). Children's problems in text comprehension: An experimental investigation. Cambridge, MA: Cambridge University Press.

Recebido em 18.10.2010

Primeira decisão editorial em 10.08.2011

Versão final em 02.07.2012

Aceito em 09.07.2012 


\section{APÊNDICE A: O TEXTO E SUAS DIVISÕES}

\begin{tabular}{|c|c|}
\hline 1 & $\begin{array}{l}\text { Pedrinho chegou da escola feliz da vida. Não tinha nenhuma lição naquele dia. Já pensou, ter uma tarde } \\
\text { inteira e mais dois dias de descanso e brincadeira? Era muita felicidade para um garoto só. Mas a felici- } \\
\text { dade ele repartia com os amigos da rua, enquanto brincava. }\end{array}$ \\
\hline 2 & $\begin{array}{l}\text { No almoço, entre uma colherada e outra do prato de arroz com feijão, foi contando as novidades: } \\
\text { - Sabe mãe, hoje tem reunião no campinho. Nós vamos decidir os times pro campeonato. Você já costu- } \\
\text { rou o emblema na minha camisa? } \\
\text { A mãe distraída, nem responde. } \\
\text { - Ô mãe! E a camisa? Tá pronta? }\end{array}$ \\
\hline 3 & $\begin{array}{l}\text { Nisso a campainha tocou três vezes seguidas. Era o Baratinha chamando pra brincar. } \\
\text { - Come logo uma banana e vai atender a porta, filho. Outra hora a gente conversa, tá? } \\
\text { Pedrinho achou esquisito esse jeito da mãe de não olhar nos olhos enquanto falava com ele. Mas a cam- } \\
\text { painha tocou novamente e ele então precisou sair, todo apressado. A mãe sentiu um aperto no coração. } \\
\text { Ele iria ficar bem triste quando soubesse. E foi logo o Baratinha quem deu a notícia. }\end{array}$ \\
\hline 4 & $\begin{array}{l}\text { - Acho que não vai ter mais campeonato nenhum, Pedro. } \\
\text { Pedrinho não acreditou. Mas era verdade. Bem em frente do campinho Seu Nicolau colocou uma tabu- } \\
\text { leta amarela anunciando: VENDE-SE. Dali a pouco chegaram as outras crianças e ficaram, todos ali, } \\
\text { pensando no que fazer. } \\
\text { - Já sei! Gritou o Pedro. - Vamos falar com Seu Nicolau }\end{array}$ \\
\hline 5 & $\begin{array}{l}\text { Mas o velho não estava para conversas. Queria mesmo vender o terreno e ponto final. Não que ele preci- } \\
\text { sasse. Era dono de muitas casas na rua, inclusive a que Pedro morava. } \\
\text { - Mas Seu Nicolau, é o único lugar que a gente tem para brincar! Na rua a mãe não deixa, na escola não } \\
\text { dá tempo, em casa nem pensar. Onde é, então, que a gente vai brincar, hein? } \\
\text { Seu Nicolau sacudiu os ombros. As crianças que procurassem outro lugar. Disse também que o terreno } \\
\text { era sujo, cheio de lixo, que não podia ficar assim, sem uso para nada. } \\
\text { Foi então que uma ideia passou voando pela cabeça de Pedro. }\end{array}$ \\
\hline 6 & $\begin{array}{l}\text { Pedro piscou pros amigos, despediu-se do velho Nicolau e, no caminho de volta, explicou pra turma o } \\
\text { que pretendia fazer. } \\
\text { Durante o sábado, Pedrinho e seus amigos trabalharam no campinho, trazendo caixotes, carregando } \\
\text { lixo, catando latas e papéis no chão, varrendo. Pedrinho pensou: Seu Nicolau vai ter uma surpresa. } \\
\text { Quando voltou pra casa já era quase noite. }\end{array}$ \\
\hline 7 & $\begin{array}{l}\text { No Domingo, ao voltar da missa, Seu Nicolau teve uma grande surpresa. O terreno à venda não parecia } \\
\text { mais o mesmo. Numa faixa improvisada lia-se: PRAÇA DO SEU NICOLAU. E todo o pessoal que } \\
\text { havia ajudado na arrumação aguardou em silêncio, esperando a reação do velho homem. Pais, mãe } \\
\text { e crianças, num só olhar. Seu Nicolau se aproximou deles, sem saber o que dizer, mas sabendo o que } \\
\text { fazer. Caminhou lentamente até a tabuleta amarela de vende-se e arrancou-a do chão com um sorriso. }\end{array}$ \\
\hline
\end{tabular}

